Review

\title{
Hybridoma-Derived Idiotype Vaccine for Lymphoma: Approval Must Wait
}

\section{Maurizio Bendandi ${ }^{\dagger}$}

Center for Applied Medical Research and University Hospital, University of Navarra, Avda. Pio XII 36-55, 31008 Pamplona, Spain; E-Mail: mbendandi@unav.es; Tel.: +34 948194700 x1004

† Current address: Simmons Comprehensive Cancer Center, University of Texas at Southwestern Medical Center, 5323 Harry Hines Blvd., Dallas, TX 75390-8590, USA;

E-Mail: maurizio.bendandi@utsouthwestern.edu; Tel.: +1 2146481803.

Received: 5 February 2010; in revised form: 3 March 2010 / Accepted: 8 March 2010 /

Published: 15 March 2010

\begin{abstract}
Hybridoma-derived idiotype vaccines have been used for the experimental treatment of human lymphoma over the last twenty years, providing evidence of biological efficacy, clinical efficacy and clinical benefit. However, the product that has come closer to regulatory approval is unlikely to clear that hurdle due to the insufficiently robust data obtained in a recently closed clinical trial. This review aims at discussing the reasons for hybridoma-derived idiotype vaccines, more difficult to produce but also more successful than recombinant idiotype vaccines so far, are unlikely to gain regulatory approval. In particular, it is necessary to examine the many peculiar features of this therapeutic approach in a broader context, with special attention to concepts like customized active immunotherapy and randomization. Most published trials based on hybridoma-derived idiotype vaccines are being analyzed, together with the yet non-peer reviewed data from the only randomized study conducted so far with this product, and with the main trials on recombinant idiotype vaccines for thorough comparison. All in all, the sole randomized trial ever conducted on hybridoma-derived idiotype vaccines failed to achieve its primary clinical end point because of an insufficient accrual and because the statistical significance achieved was not as stringent as required for regulatory approval.
\end{abstract}

Keywords: hybridoma; idiotype; immune response; lymphoma; randomized trials; recombinant; vaccine 


\section{Introduction}

The estimated 66,000 new cases over this year make of non-Hodgkin's lymphoma (NHL) the most common hematologic malignancy in the United States [1]. While significant epidemiological differences exist in different geographic regions, among B-cell NHL subtypes follicular lymphoma (FL) represents about $29 \%$ of cases, while mantle cell lymphoma (MCL) accounts for about $7 \%$ of them [2]. These two B-cell NHL subtypes are the sole in which hybridoma-derived idiotype vaccines have been tested so far, with the former having been the subject of the vast majority of such clinical trials [3]. However, at least in principle, any B-cell NHL subtype whose cells express on their surface either a complete clonal immunoglobulin or at least some of its idiotopes [4] could be treated with an idiotype vaccine with the aim of preventing disease relapse once a clinical response has been achieved through standard of care therapy [5].

While quite different from a clinical and biological standpoint, both FL and MCL are still considered incurable, and even though many more therapeutic tools are available for the former, indolent type of cancer [6], in both cases it is safe to state that a successful, innocuous [7], patientspecific and therefore customized vaccination strategy like that targeting the lymphoma-specific idiotype would definitely fulfill the criteria of responding to an unmet medical need. Indeed, upon demonstration of clinical efficacy and benefit, no other currently available treatment could compare with idiotypic vaccination in terms of safety profile [6].

\section{Overview of the market}

Most cases of B-cell NHL remain incurable. However, the more indolent the subtype is, the more likely subsequent clinical remissions may be achieved through several therapeutic options. This is particularly true in the case of FL [8], the most classical field of application of idiotypic vaccination [3]. Over the last decade, the anti-CD20 monoclonal antibody rituximab has revolutionized the way oncologists treat FL, MCL and virtually any other CD20-positive B-cell NHL, to such an extent that the combination of rituximab and different chemotherapy regimens is now the standard of care for most if not all B-cell lymphoma [6]. In particular, with these combinations both higher response rates and longer response duration are systematically achieved compared to those obtained by chemotherapy alone [6]. Other novel agents, including new monoclonal antibodies targeting CD20 or other surface antigens [6], are also approaching the final stages of their development. However, neither rituximab nor any of them seem to have the potential to cure most if not all patients with indolent Bcell NHL. Many patients tend to develop resistance upon retreatment [9] and/or to suffer from the side effects. In this respect, even use of the generally safe rituximab is not entirely devoid of them, particularly when employed for an extensive period of time as a maintenance treatment. Progressive multifocal leukoencephalopathy is as rare as invariably and rapidly lethal, while the full implications of the long-term immune suppression associated with the use of rituximab has not yet been evaluated due to the relatively short follow-up of most trials on rituximab maintenance [6].

All in all, as mentioned above, we still need therapeutic tools that may be both curative and completely safe for at least a portion of patients with B-cell NHL. Idiotype vaccines are serious candidates to prove possessing both these features, and among them hybridoma-derived idiotype 
vaccines are those with the longest track record (Table 1), although none of them has yet either made it to the market or gained regulatory approval [3].

Table 1. Major studies on hybridoma-derived idiotype vaccine for lymphoma. Legend: Id: idiotype; KLH: keyhole limpet hemocyanin; FL: follicular lymphoma; MCL: mantle cell lymphoma.

\begin{tabular}{|c|c|c|c|c|c|c|c|}
\hline Institution/Sponsor & Idiotype Production & $\begin{array}{l}\text { Vaccine } \\
\text { Formulation }\end{array}$ & Disease & $\begin{array}{l}\text { Biological } \\
\text { Efficacy }\end{array}$ & $\begin{array}{l}\text { Clinical } \\
\text { Efficacy }\end{array}$ & $\begin{array}{l}\text { Clinical } \\
\text { Benefit }\end{array}$ & Reference \\
\hline Stanford University & Hybridoma & Id-KLH + SAF-1 & FL & YES & N/A & N/A & [23] \\
\hline NCI & Hybridoma & Id-KLH + GM-CSF & MCL & YES & N/A & N/A & [37] \\
\hline NCI & Hybridoma & Id-KLH + GM-CSF & FL & YES & YES & N/A & [24] \\
\hline $\begin{array}{l}\text { Puerta de Hierro } \\
\text { Hospital }\end{array}$ & Hybridoma & Id-KLH + GM-CSF & FL & YES & YES & N/A & {$[25]$} \\
\hline $\begin{array}{l}\text { University of } \\
\text { Navarra }\end{array}$ & Hybridoma & Id-KLH + GM-CSF & FL & YES & N/A & YES & {$[26]$} \\
\hline Biovest & $\begin{array}{l}\text { Hybridoma/AutovaxId } \\
\text { /BiovaxId }\end{array}$ & Id-KLH + GM-CSF & FL & pending & pending & YES & [31] \\
\hline
\end{tabular}

\section{Introduction to the Compound}

Most idiotype vaccines, including those whose idiotype is rescued from hybridomas, currently consist of three ingredients [3]: an idiotype-containing immunoglobulin, an immunogenic carrier like keyhole limpet hemocyanin (KLH), and immunologic adjuvant like granulocyte-macrophage colonystimulating factor (GM-CSF).

The idiotype (Figure 1) is defined as the collection of idiotopes, that is the collection of all epitopes solely found on the hypervariable regions of an immunoglobulin [10-11]. As such, the idiotype defines the clonality of each and every immunoglobulin, including those expressed by B-cell NHL [3]. As a consequence, most B-cell NHL clones feature a patient- and tumor-specific idiotype, which can be used as cancer vaccine antigen and targeted in a customized fashion [12]. So far, the most important idiotype vaccine trials have been conducted using soluble protein, idiotype-containing full immunoglobulins [3].

$\mathrm{KLH}$ is a natural and powerful immunogenic carrier extracted from the mollusk Megathura Crenulata and used in humans now for decades without any type of clinical or biological concern [13]. GM-CSF is a hematopoietic growth factor that, besides stimulating myeloid cell maturation, is also known to attract dendritic cells at the site of an antigen injection (function not possessed by the more widely used alternative, that is G-CSF), and as such is commonly used as an immunologic adjuvant [14].

\section{Chemistry}

While a few clinical studies have already been conducted using recombinant idiotype vaccines [3], the hybridoma-based rescue of patient- and tumor-specific idiotypes relies on an entirely different methodology [3], certainly more tedious and far less straightforward [15-16] even when partly streamlined and automated through the development of cell growth instruments [17]. However, at the time of this writing hybridoma-derived idiotype vaccines have shown biological efficacy, clinical 
efficacy and clinical benefit in lymphoma patients, while the recombinant alternatives have shown only biological efficacy [3].

Figure 1. Schematic representation of the structure of a monomeric immunoglobulin. The collection of idiotopes termed idiotype is located within both heavy and light chain variable regions. $\mathrm{VH}$ : heavy chain variable region; $\mathrm{VL}$ : light chain variable region; $\mathrm{CH}$ : heavy chain constant region; CL: light chain constant region; CDR: complementaritydetermining region.

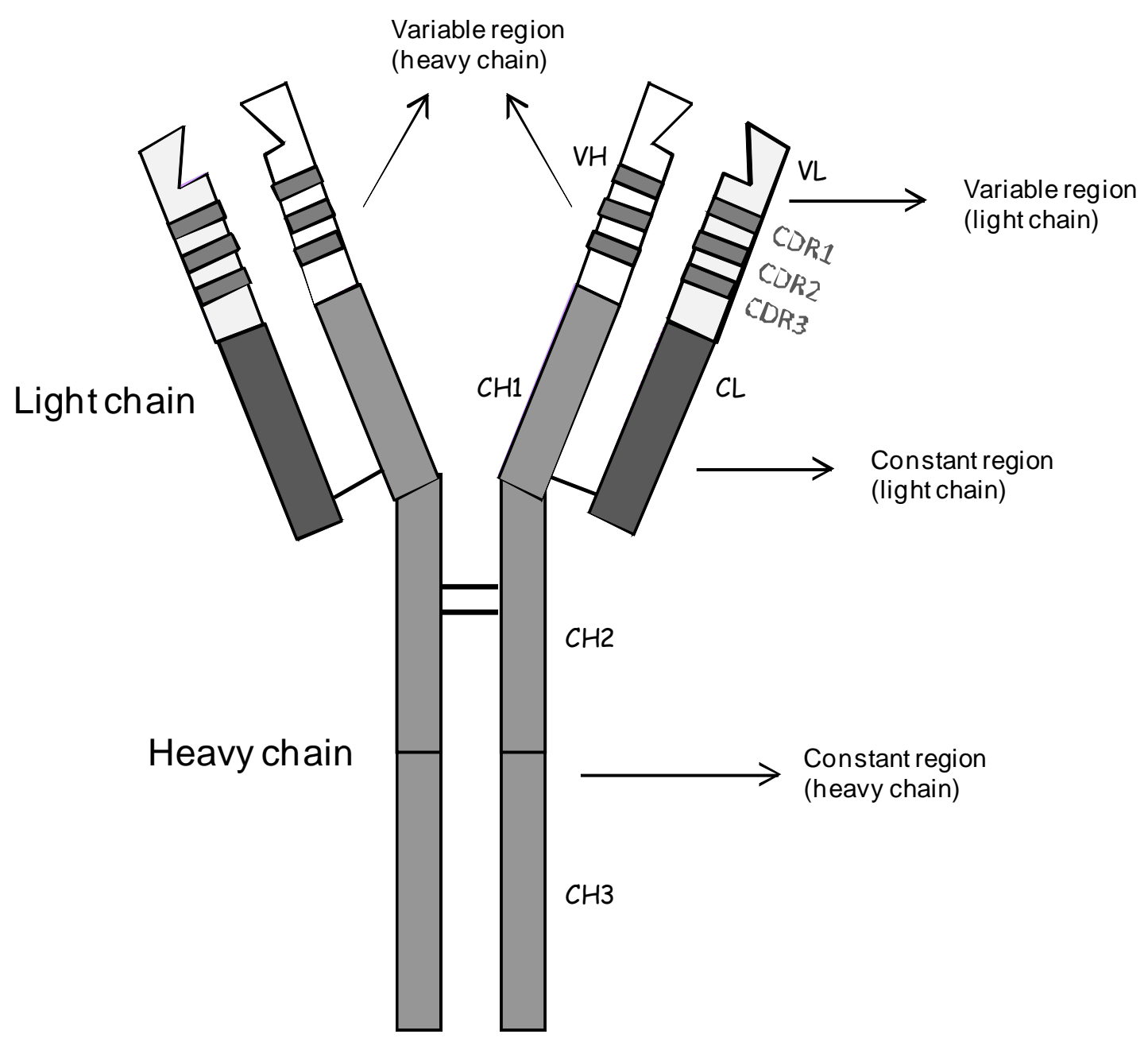

As opposed to recombinant idiotypes, which are mounted on a shared, tumor- and potentially isotype-unrelated immunoglobulin heavy chain scaffold [3], hybridoma-methodology allows the reproduction in the lab of the original and unique, idiotype-containing tumor immunoglobulin [3]. In neither version of the tumor-specific idiotype, however, it is possible to reproduce the same idiotype glycosylation [18-20] pattern as it is present on the idiotype expressed on the surface of the lymphoma cell [3]. It is not fully known whether these types of difference may affect the immunogenicity of an idiotype vaccine and/or the relevance of a vaccine-induced immune response to the tumor antigen actually expressed on the tumor cell membrane. The limited data available in this respect seem to confirm that they do not [3], but further research is certainly warranted. 
Once the tumor-specific idiotype has been reproduced, it is subjected to conjugation with KLH through the use of either glutharaldeide or maleimide [3]. So far, only the former has been employed for the development of clinical grade idiotype vaccines to be used in clinical trials. GM-CSF is administered separately subcutaneously over few days at the same site where the idiotype-KLH conjugate has been also administered subcutaneously on the first day of the vaccination cycle [3].

\section{Pharmacodynamics}

Typically, idiotype vaccines are administered at a dose of $1 \mathrm{mg}$ ( $0.5 \mathrm{mg}$ of idiotype conjugated with $0.5 \mathrm{mg}$ of $\mathrm{KLH}$ ) on day 0 of each vaccination cycle, while GM-CSF is administered together with the vaccine at a dose which may vary from trial to trial [3]. The frequency and duration of these vaccination cycles may also vary from trial to trial [3], sometimes even constantly over several years [7].

As discussed elsewhere [7], an idiotype vaccine for lymphoma is not a drug in its common definition. It is rather a customized pharmacological agent meant to do per se little or nothing to both normal and tumor cells. The sole purpose of its combination of ingredients is that of eliciting an idiotype-specific immune response possibly capable of eliminating the tumor cells of one patient at a time. Irrespective of whether such an ambitious goal is or is not achieved by this type of customized active immunotherapy, the side effects are absent or minimal, self-limiting and typically local, although mild flu-like symptoms have also been reported in a minority of patients as due to GM-CSF [7].

\section{Pharmacokinetics and Metabolism}

Similarly, the destine of any of the three proteins comprised in the vaccine formulation (idiotype, $\mathrm{KLH}$ and GM-CSF) is not expected to be different from that of any other vaccine protein administered subcutaneously, beginning with the uptake from professional antigen-presenting cells.

It has to be noted that both the self/non-self and the danger model [21] seem to fall short in explaining the basic way of functioning of idiotype vaccines. The former because it does not explain why it is still possible to allure the immune system into recognizing a self antigen, the idiotype, as if it were non-self by simply conjugating it with a bona fide non-self antigen like KLH. The latter because, assuming that repeated administrations of idiotype-KLH (where KLH is supposed to represent the danger signal) are responsible for the circumvention of the self/non-self issue, then this strategy should work in all patients endowed with a relatively normal immune function. However, this is not the case, as a non-negligible fraction of such vaccinated patients still fails to develop an idiotype-specific immune response in spite of normally reacting to KLH [10-11].

\section{Clinical efficacy and benefit}

After showing biological efficacy [3] in several phase-I and -II studies over the last twenty years [22-26], hybridoma-derived idiotype vaccines have more recently shown also clinical efficacy [3] in a couple of phase-II trials [24-25] and even clinical benefit in a single phase-II trial [26]. In particular, it is now well established that most patients receiving a hybridoma-derived idiotype vaccine develop an idiotype-specific humoral and/or cellular immune response [22-26]. Moreover, these vaccine-induced, specific immune responses are often associated with the clearance in vivo [3] of tumor cells that had 
survived pre-vaccine chemotherapy [24-25]. Finally, a single study was designed to show that, contrary to the knowledge gathered over 50 years of clinical research in follicular lymphoma [27], immunization with a hybridoma-derived idiotype vaccine was capable of prolonging postchemotherapy (without rituximab) second complete responses in FL patients well beyond its typical average duration (13 months), as well as beyond the duration of the post-chemotherapy (with/without rituximab) first complete response in each and every patient with a vaccine-induced, idiotype-specific immune response [26]. Indeed, 20/20 patients who developed such an immune response achieved this dual goal in a highly statistical fashion, while the $5 / 5$ who did not develop such an immune response failed to achieve either result. Of course, this novel way to show clinical benefit of a customized type of active immunotherapy has raised some generic objections [28-29]. However, as discussed elsewhere [3,30], these criticisms cannot withstand a deeper and unbiased analysis of the actual clinical data.

The only phase-III trial ever conducted to test hybridoma-derived idiotype vaccines [31] has recently failed to achieve its main clinical endpoint for reasons that are completely unrelated to the actual vaccine effectiveness [3]. Appropriately designed to offer either the customized, soluble protein, hybridoma-derived idiotype vaccine (BiovaxId ${ }^{\mathrm{TM}}$, Biovest International, Inc.) or a placebo control only to follicular lymphoma patients in first complete response [3], this study did not include a sufficiently effective and popular pre-vaccine chemotherapy regimen [3]. As a consequence, and as predicted [32], it ultimately failed to both enroll enough patients and to achieve the highly statistical significance required in this particular context for regulatory approval of this type of customized active immunotherapy [3]. In particular (Table 2), the trial enrolled 234 patients instead of the planned 629 (later revised to 563), randomized 177 (but only 117 ever made it to receive either the experimental or the control product) instead of 375, actually provided at least one dosis of the idiotype vaccine to 76 instead of 250, and had only 41 instead of 125 receiving the control product [31-33].

Table 2. Comparison between approval requirements and actual achievements of the phase-III randomized trial on BiovaxId ${ }^{\mathrm{TM}}$. Legend: pts: patients; ITT: intent to treat; RFS: relapse-free survival.

\begin{tabular}{|c|c|c|}
\hline Variable & Planned & Actual \\
\hline Accrual & 629 (later revised to 563) pts & 234 pts \\
\hline Randomization & 375 pts & $\begin{array}{l}177 \text { (later reduced to } 117 \text { on a } \\
\text { modified ITT basis) pts }\end{array}$ \\
\hline Vaccinated (5 doses) & 250 pts & 76 pts (at least 1 dose) \\
\hline Control product & 125 pts & $41 \mathrm{pts}$ \\
\hline $\begin{array}{l}\text { Required statistical significance } \\
\text { (difference in RFS) }\end{array}$ & $\mathrm{p}<0.01$ & $p=0.045$ \\
\hline
\end{tabular}

Notably, the vast majority of the 60 randomized patients who never had a chance to receive either treatment lost such an opportunity due to an early relapse [31]. Therefore, exactly 50\% of all enrolled patients were unable to proceed with the crucial portion of the trial because pre-vaccine chemotherapy failed to induce or maintain a durable first complete response before vaccination could even start [3]. Since the data of this study have not yet been published in the peer-reviewed literature, it is impossible to ascertain how many patients actually completed the vaccination schedule and how many received 
fewer vaccinations than planned. In any case, the relapse-free survival of vaccinated patients was statistically significantly longer $(\mathrm{p}=0.045)$ than that of patients who received the placebo control [31]. However, this statistical significance fell very short of the threshold of highly statistical significance (p, 0.01) previously established as necessary for regulatory approval, since no back-up trial had been planned [3].

All in all, the data of this trial further support the notion of clinical benefit of idiotypic vaccination in follicular lymphoma [26]. However, given the important pitfalls accumulated throughout the several years during which the study remained open, they are unlikely to provide ground for regulatory approval [3]. After all, had the trial succeeded in enrolling all planned patients, statistical significance of the difference in relapse-free survival could have improved, disappeared or remained unchanged [30].

\section{Safety and Tolerability}

Several hundreds of patients have now being vaccinated with different types of recombinant and hybridoma-derived idiotype vaccine [3]. It is now clear that these products are very safe and tolerable, with negligible side effects even when administered periodically over several years [7].

\section{Regulatory affairs}

Recently, all three randomized clinical trials (Table 3) conducted to confirm clinical benefit of idiotypic vaccination in follicular lymphoma, that is the study described above and two other using recombinant vaccines, have failed to achieve their main endpoints [31,34-35]. These predicted [32] and unfortunate outcomes could be explained on the basis of so many pitfalls intrinsic to each single study design and conduction that, nevertheless, it is impossible to firmly conclude whether any or all of these different vaccines [3] are or are not effective products [3,32-33].

Table 3. Main features of all randomized clinical trials on idiotypic vaccination. Legend: Legend: CR: complete response; PR: partial response; SD: stable disease; DFS: diseasefree survival; TTP: time to progression; PFS: progression-free survival; ITT: intent to treat; n.s.: non-significant; CVP: cyclophosphamide, vincristine and prednisone; PACE: prednisone, doxorubicin, cyclophosphamide and etoposide.

\begin{tabular}{|c|c|c|c|c|c|}
\hline Pre-Vaccine Therapy & $\begin{array}{l}\text { Patient Status Before } \\
\text { Vaccination }\end{array}$ & $\begin{array}{l}\text { Accrual } \\
\text { (planned / } \\
\text { actual) } \\
\end{array}$ & Endpoint & $\begin{array}{l}\text { Results (required } \\
\text { / obtained) }\end{array}$ & Reference \\
\hline CVP (8 cycles) & First CR or PR & 360 / 285 & PFS & $\mathrm{p}<0.01 / \mathrm{p}=$ n.s. & 34 \\
\hline Rituximab (4 doses) & First $\mathrm{CR}$ or $\mathrm{PR}$ or $\mathrm{SD}$ & 342 / 345 & ТTP & $\mathrm{p}<0.01 / \mathrm{p}=$ n.s. & 35 \\
\hline $\begin{array}{l}\text { PACE ( } 90 \% \text { of pts) or } \\
\text { Rituximab-CHOP ( } 6 \\
\text { cycles) }\end{array}$ & First CR & $\begin{array}{l}375 \text { / } 117 \\
\text { (modified ITT) }\end{array}$ & DFS & $\begin{array}{l}\mathrm{p}<0.01 / \mathrm{p}= \\
0.045\end{array}$ & 31 \\
\hline
\end{tabular}

Even more important, the very same concept of randomization as a viable and meaningful tool to assess clinical benefit of idiotypic vaccination or any other customized active immunotherapy requires deeper and less biased questioning [3]. In facts, contrary to standard randomized trials where all patients within a same treatment group receive indeed the same therapy, in this case this statement holds true only for the control arm [8]. In the experimental arm, each and every patient receives a 
unique, different and differently immunogenic product, which is per se inactive against the tumor while supposed to stimulate a unique and different immune system that is in itself intrinsically prone to be more or less different at the time of each and every immunization [3]. In a sense, idiotypic vaccination, like any other customized active immunotherapy, challenges us with the ultimate “customized setting”, in which nearly all major biological variables - treatment (the idiotype), effector system (every time the vaccine is administered) and disease (particularly in the case of the clinically very heterogeneous follicular lymphoma) - are truly customized, and as such, arguably impossible to be subjected to the rigid constrains of randomization. In these extreme conditions, even studies theoretically well designed [31] may be ultimately doomed to fail simply because clearly unfeasible [32].

\section{Conclusions}

After showing biological efficacy, clinical efficacy and clinical benefit [3], a hybridoma-derived idiotype vaccine is likely to fail to obtain regulatory approval for marketing due to the fact that the sole large-scale clinical trial that aimed at such a goal failed to achieve its main endpoint. With the substantial limitations of an insufficient patient accrual and of a limited statistical significance, this study nevertheless confirms the conclusions of a previous report of clinical benefit associated with idiotypic vaccination in follicular lymphoma [26].

The development of idiotype vaccines has temporarily come to an abrupt stalemate. Hybridoma methodology is unlikely to represent the basis for further testing of idiotypic vaccination in large scale clinical trials. Recombinant technology, in spite of the initial lack of success [34-35], may still provide ground for a renewed sense of hope for idiotype vaccines to be used in better designed and better conducted clinical trials [3]. In particular, new studies are being planned that employ recombinant idiotype proteins rapidly and effectively produced in plants [36]. Should these projects succeed, of course it would remain to be determined whether idiotypic vaccination may have a role in B-cell malignancies other than follicular lymphoma [37-38]. Most of these open questions might be answered over the next decade.

All in all, in the subset of patients with lymphoma in which it works, idiotypic vaccination is meant to represent a virtually innocuous maintenance treatment to be used after tumor shrinkage achieved by other pre-vaccine treatments: some to be preferred because non heavily immune suppressive, others not to because of their associated long-lasting B- or T-cell depletion [3,6]. In the maintenance setting, a successful idiotype vaccine would have to minimally compete with the far more toxic interferon and, above all, with the far more popular (although not devoid of relevant long-term toxicity) rituximab [3,6].

In most B-cell lymphoma, rituximab has shown best results when used in combination with standard chemotherapy in the first-line treatment, while its potential is clearly diminished upon reusage at subsequent relapses [3,6]. Vice versa, idiotypic vaccination has shown its potential also in first relapse patients, provided that the subsequent pre-vaccine treatment was not accompanied by profound immune suppression. Therefore, should an idiotype vaccine make it to the market of indolent lymphoma, a potential long-term strategy might include both types of maintenance treatment at different time points. Alternatively, should the sequential use of rituximab (with or without chemotherapy) and idiotypic vaccination be considered within the same line of treatment, it might be important that, in the patients who do not experience an early relapse, substantial B-cell recovery be 
allowed before starting the latter procedure [3], although the evidence supporting this opinion is currently only indirect [35,37].

A major logistical difference between active (vaccine) and passive (rituximab and other monoclonal antibodies) immunotherapy of B-cell malignancies is that the former has to be provided on a customized basis and requires adequate tumor sample handling to assure that the individualized vaccine is properly produced, while the other is already available on an off-the-shelf basis.

Another aspect of idiotypic vaccination that will require further refinement is the way by which we assess and monitor vaccine-induced and idiotype-specific immune responses. Whether we refer to the arbitrary definitions of positive and negative humoral responses as measured by standard ELISA [30] or to the plethora of non-standardized methods used to document cellular responses [26], there is definitely room for conspicuous improvement.

Notwithstanding all these hurdles still to be overcome by idiotypic vaccination, the push to make them available to the patients remains unwavering, particularly considering that, as opposed to virtually any other cancer treatment, when effective it has basically no side effects; and when ineffective also [3].

\section{References}

1. Jemal, A.; Siegel, R.; Ward, E; Hao, Y.; Xu, J.; Thun, M.J. Cancer statistics, 2009. CA Cancer J. Clin .2009, 59, 225-249.

2. Jaffe, E.S.; Harris, N.L.; Stein, H.; Campos, E.; Pileri, S.A.; Swerdlow, S.H. Introduction and overview of the classification of the lymphoid neoplasms. In WHO Classification of Tumours of Haematopoietic and Lymphoid Tissues, 4th ed.; Swerdlow, S.H., Campos, E., Harris, N.L., Jaffe, E.S., Pileri, S.A., Stein, H., Thiele, J., Vardiman, J.W., Eds.; IARC Press: Lyon, France, 2008; pp. 157-166.

3. Bendandi, M. Idiotype vaccines for lymphoma: proof-of-principles and clinical trial failures. Nat. Rev. Cancer 2009, 9, 675-681.

4. Bendandi, M. Anti-idiotype vaccines for human follicular lymphoma. Leukemia 2000, 14, 13331339.

5. Inogés, S.; Rodríguez-Calvillo, M.; López-Díaz de Cerio, A.; Zabalegui, N.; Pérez-Calvo, J.; Panizo, C.; Hernandez, M.; Cuesta, B. Rocha, E.; Bendandi, M. Feasibility of idiotype vaccination in relapsed B-cell malignancies. Haematologica 2003, 88, 1438-1440.

6. Bendandi, M. Aiming at a curative strategy for follicular lymphoma. CA Cancer J. Clin. 2008, 58, 305-317.

7. Inogés, S.; López-Díaz de Cerio, A.; Zabalegui, N.; Soria, E.; Villanueva, H.; Panizo, C.; Rodriguez-Caballero, A.; Suarez, L.; Pastor, F.; Rodriguez-Calvillo, M.; et al. Prolonged idiotypic vaccination against follicular lymphoma. Leuk Lymphoma 2009, 50, 47-53.

8. Longo, D.L. Idiotype vaccination in follicular lymphoma: knocking on the doorway to cure. $J$. Natl. Cancer Inst. 2006, 98, 1263-1265.

9. Hagenbeek, A. Monoclonal antibodies (update): CD20, rituximab. Hematol. Meeting Rep. 2008, 2, 50-51. 
10. Bendandi, M. Role of anti-idiotype vaccines in the modern treatment of human follicular lymphoma. Expert. Rev. Anticancer Ther. 2001, 1, 65-72.

11. Bendandi, M. The role of idiotype vaccines in the treatment of human B-cell malignancies. Expert. Rev. Vaccines 2004, 3, 163-170.

12. de Cerio, A.L.; Zabalegui, N.; Rodríguez-Calvillo, M.; Inoges, S.; Bendandi, M. Anti-idiotype antibodies in cancer treatment. Oncogene 2007, 26, 3594-3602.

13. Harris, J.R.; Markl, J. Keyhole limpet hemocyanin: molecular structure of a potent marine immunoactivator. A review. Eur. Urology 2000, 37 (Suppl. 3), 24-33.

14. Kwak, L.W.; Young, H.A.; Pennington, R.W.; Weeks, S.D. Vaccination with syngeneic, lymphoma-derived immunoglobulin idiotype combined with granulocyte/macrophage colonystimulating factor primes mice for a protective T cell response. Proc. Natl. Acad. Sci. USA 1996, 93, 10972-10977.

15. Carroll, W.L.; Thielemans, K.; Dilley, J.; Levy, R. Mouse x human heterohybridomas as fusion partners with human B-cell tumors. J. Immunol. Methods 1986, 89, 61-72.

16. Rodríguez-Calvillo, M.; Inogés, S.; López-Díaz de Cerio, A.; Zabalegui, N.; Villanueva, H.; Bendandi, M. Variations in "rescuability" of immunoglobulin molecules from different forms of human lymphoma: implications for antiidiotype vaccine development. Crit. Rev. Oncol. Hematol. 2004, 52, 1-7.

17. De Palma, A. Vaccine manufacturing reborn. Pharmaceutical Manufacturing 2007, available at: http://www.pharmamanufacturing.com/articles/2007/051.html?page=full/, accessed on March 12, 2007.

18. Zhu, D.; McCarthy, H.; Ottensmeier, C.H.; Johnson, P.; Hamblin, T.J.; Stevenson, F.K. Acquisition of potential N-glycosylation sites in the immunoglobulin variable region by somatic mutation is a distinctive feature of follicular lymphoma. Blood 2002, 99, 2562-2568.

19. Zabalegui, N.; de Cerio, A.L.; Inogés, S.; Rodríguez-Calvillo, M.; Pérez-Calvo, J.; Hernández, M.; García-Foncillas, J.; Martín-Algarra, S.; Rocha, E.; Bendandi, M. Acquired potential Nglycosylation sites within the tumor-specific heavy chains of B-cell malignancies. Haematologica 2004, 89, 541-546.

20. Radcliffe, C.M.; Arnold, J.N.; Suter, D.M.; Wormald, M.R.; Harvey, D.J.; Royle, L.; Mimura, Y.; Kimura, Y.; Sim, R.B.; Inogès, S.; et al. Human follicular lymphoma cells contain oligomannose glycans in the antigen-binding site of the B-cell receptor. J. Biol. Chem. 2007, 282, 7405-7415.

21. Matzinger, P. The danger model: a renewed sense of self. Science 2002, 296, 301-305.

22. Kwak, L.W.; Campbell, M.J.; Czerwinski, D.K.; Hart, S.; Miller, R.A.; Levy, R. Induction of immune responses in patients with B-cell lymphoma against the surface-immunoglobulin idiotype expressed by their tumors. $N$ Engl. J. Med. 1992, 327, 1209-1215.

23. Hsu, F.J.; Caspar, C.B.; Czerwinski, D.; Kwak, L.W.; Liles, T.M.; Syrengelas, A.; TaidiLaskowski, B.; Levy, R. Tumor-specific idiotype vaccines in the treatment of patients with B-cell lymphoma-long-term results of a clinical trial. Blood 1997, 89, 3129-3135.

24. Bendandi, M.; Gocke, C.D.; Kobrin, C.B.; Benko, F.A.; Sternas, L.A.; Pennington, R.; Watson, T.M.; Reynolds, C.W.; Gause, B.L.; Duffey, P.L.; et al. Complete molecular remissions induced by patient-specific vaccination plus granulocyte-monocyte colony-stimulating factor against lymphoma. Nat. Med. 1999, 5, 1171-1177. 
25. Barrios Y, Cabrera R, Yáñez R, Briz M, Plaza A, Forés R, Fernández MN, Díaz-Espada F. Antiidiotypic vaccination in the treatment of low-grade B-cell lymphoma. Haematologica 2002, 87, 400-407.

26. Inogès, S.; Rodrìguez-Calvillo, M.; Zabalegui, N.; Lòpez-Dìaz de Cerio, A.; Villanueva, H.; Soria, E.; Suárez, L.; Rodríguez-Caballero, A.; Pastor, F.; García-Muñóz, R.; et al. Clinical benefit associated with idiotypic vaccination in patients with follicular lymphoma. J. Natl. Cancer Inst. 2006, 98, 1292-1301.

27. Longo, D.L. Idiotype vaccination in follicular lymphoma: knocking on the doorway to cure. $J$. Natl. Cancer Inst. 2006, 98, 1263-1265.

28. Houot, R., Levy, R. Vaccines for lymphomas: idiotype vaccines and beyond. Blood Rev. 2009, 23, 137-142.

29. Foglietta, M.; Neelapu, S.S.; Kwak, L.W. Therapeutic vaccines for lymphoma: from bench to bedside. In ASCO 2009 Educational Book; American Society of Clinical Oncology: Orlando, FL, USA, 2009; pp. 495-500.

30. Inogés, S.; López-Díaz de Cerio, A.; Soria, E.; Villanueva, H.; Pastor, F.; Bendandi, M. Idiotype vaccines for human B-cell malignancies. Curr. Pharm. Design 2010, 16, 300-307.

31. Schuster, S.J.; Neelapu, S.S.; Gause, B.L.; Muggia, F.M.; Gockerman, J.P.; Sotomayor, E.M.; Winter, J.N.; Flowers, C.R.; Stergiou, A.M.; Kwak, L.W. Idiotype vaccine therapy (BiovaxID) in follicular lymphoma in first complete remission: Phase III clinical trial results. J. Clin. Oncol. 2009, 27, 18s.

32. Bendandi, M. Clinical benefit of idiotype vaccines: too many trials for a clever demonstration? Rev. Recent Clin. Trials 2006, 1, 67-74.

33. López-Díaz de Cerio, A, Inogés, S. Future of idiotypic vaccination for B-cell lymphoma. Expert Rev .Vaccines 2009, 8, 43-50.

34. Levy, R.; Robertson, M.J.; Ganjoo, K.; Leonard, J.; Vose, J.; Denney, D.J. Results of a Phase 3 trial evaluating safety and efficacy of specific immunotherapy, recombinant idiotype (Id) conjugated to KLH (Id-KLH) with GM-CSF, compared with non-specific immunotherapy, KLH with GM-CSF, in patients with follicular non-Hodgkin's lymphoma (fNHL). AACR Meeting Abstracts 2008, Abstract LB-204.

35. Freedman, A.; Neelapu, S.S.; Nichols, C.; Robertson, M.J.; Djulbegovic, B.; Winter, J.N.; Bender, J.F.; Gold, D.P.; Ghalie, R.G.; Stewart, M.E.; et al. Placebo-Controlled Phase III Trial of PatientSpecific Immunotherapy With Mitumprotimut-T and Granulocyte-Macrophage ColonyStimulating Factor After Rituximab in Patients With Follicular Lymphoma. J. Clin. Oncol. 2009, 27, 3036-3043.

36. Bendandi, M.; Marillonnet, S.; Kandzia, R.; Thieme, F.; Nickstadt, A.; Herz, S.; Frode, R.; Inoges, S.; Lopez-Diaz de Cerio, A.; Soria, E.; et al. Rapid, high-yield production in plants of individualized idiotype vaccines for non-Hodgkin’s lymphoma, Ann. Onc. 2010, submitted.

37. Neelapu, S.S.; Kwak, L.W.; Kobrin, C.B.; Reynolds, C.W.; Janik, J.E.; Dunleavy, K.; White, T.; Harvey, L.; Pennington, R.; Stetler-Stevenson, M.; et al. Vaccine-induced tumor-specific immunity despite severe B-cell depletion in mantle cell lymphoma. Nat. Med. 2005, 11, 986-991. 
38. Bendandi, M.; Rodríguez-Calvillo, M.; Inogés, S.; López-Díaz de Cerio, A.; Pérez-Simón, J.A.; Rodríguez-Caballero, A.; García-Montero, A.; Almeida, J.; Zabalegui, N.; Giraldo, P.; et al. Combined vaccination with idiotype-pulsed allogeneic dendritic cells and soluble protein idiotype for multiple myeloma patients relapsing after reduced-intensity conditioning allogeneic stem cell transplantation. Leuk. Lymphoma 2006, 47, 29-37.

(C) 2010 by the authors; licensee Molecular Diversity Preservation International, Basel, Switzerland. This article is an open-access article distributed under the terms and conditions of the Creative Commons Attribution license (http://creativecommons.org/licenses/by/3.0/). 